Vol. XXI, No. 62, 2021

https://doi.org/ 10.52685/cjp.21.62.3

Received: November 9, 2020

Accepted: July 27, 2021

\title{
Aesthetic Eating
}

ADAM ANDRZEJEWSKI

University of Warsaw, Warsaw, Poland

The aim of this paper is to sketch a framework for perceiving the act of consumption as an aesthetic phenomenon. I shall argue that, under some circumstances, it is possible to receive aesthetic satisfaction from the act of eating food, in which the object of one's appreciation is, for the most part, considered separately from what is actually eaten. I propose to call such a process "aesthetic eating" and argue that due to its aesthetic autonomy it might be a potential factor in enjoying certain kinds of food. This phenomenon is apparent in the case of the types of food that are acquired tastes. It is plausible that distinguishing the aesthetic pleasures of food from the ones associated with the act of eating can not only enrich our aesthetic life but also deepen the aesthetics of our overall gustatory experience.

Keywords: Gustatory aesthetics; food; aesthetic experience; aesthetic pleasure; Richard Shusterman.

"I am a bread of life"

John 6:48

\section{Introduction}

In the film Gold Rush (dir. Charlie Chaplin, 1925) viewers can admire a famous scene in which the main character portrayed by Chaplin is cooking and eating his own shoe. The boot is prepared in a pan with much attention and care. When it is ready and seasoned with watery gravy, it is served to the table, divided into two portions and consumed. At the very beginning, the protagonist seems to be slightly reluctant to the taste but after a few bites the situation changes drastically and a proper feast begins. Chaplin enjoys the shoe with true devotion, tastes all of its fragments and combines different elements to maximize the 
flavour. His gentle moves resemble eating a roasted chicken, fried fish, or delicious spaghetti, and the scene ends as a picture of full gustatory immersion into the unusual meal.

Despite the undoubtedly humorous aspect of the described scene, there is philosophical content to be found in it as well. It seems that Chaplin takes pleasure not only from the object consumed (sic!) but also from the way in which it was consumed. ${ }^{1}$ Eating a shoe is-naturally-a substantially exaggerated example but thanks to its extremity, it provokes one to ask the question: What are the aesthetic and gustatory qualities of the act of eating and of the dish itself? In particular, (how) is it possible to separate pleasures of the act of eating from what is eaten? So far, food aesthetics have concentrated on the artistic and aesthetic status of cuisines, exploring their potential to exist within the world of art and the gastronomy scene, as well as on food's sensory dimension (see Perullo 2016; Mancioppi and Perullo 2020; Jacques 2015; Jacques and Adrià 2015). Although a great level of thought precision has been reached when it comes to edible objects, e.g. whether they are artworks (Andina and Barbero 2018) or culinary recipes, e.g. how they exist (Borghini 2014, 2015), not much attention has been given exclusively to the aesthetic potential of the act of eating itself.

Recently, this gap has been filled to some extent by the contribution of Richard Shusterman. By developing this topic Shusterman attempts "[...] to introduce a bit more precision in gastronomical theory by focusing on the art of eating in a more restricted sense and by distinguishing that sense from other meanings of the term." (2016: 261). In particular, he wants to distinguish-as he labels it - the art of eating from the art of cuisine (culinary objects, resp. dishes) and the art of food appreciation and food criticism (food writings). In his proposal, Shusterman highlights the features of the art of eating as a process of food consumption that goes beyond the qualities exemplified in food; a number of reasons is given for distinguishing the art of eating from other ways of food ingestion. ${ }^{2}$

In this paper I would like to go one step further and make room for a more liberal take on food consumption than the one proposed by Shusterman. While I do not intend to criticize Shusterman's proposal per se, I will offer its substantial re-reading that goes beyond his initial claims. My observation is that Shusterman is still too focused on food itself in his proposal. Therefore, I shall argue that it is possible to think of such a way of eating in which what gets appreciated is, for the most part, considered separately from what is actually eaten. That is,

${ }^{1}$ It would like to distinguish between the pleasure taken from watching $\mathrm{x}$ and the pleasure received when actually doing $\mathrm{x}$. Thus, the subject of my considerations are not the aesthetic experiences and pleasures received when watching someone else eating.

${ }^{2}$ I use the term "food consumption" as an umbrella concept covering all modes of eating and drinking (e.g. aesthetic, religious, social, nutritional etc.). For the sake of simplicity I qualify beverage consumption as part of food consumption. 
in such a way of eating we value the qualities of the process and not the qualities of food itself (although such a situation is quite rare in everyday life). I suggest to label this process "aesthetic eating" and shall propose two understandings of it: a weak and a strong one. My thesis is supported theoretically by recent developments in process aesthetics (Nguyen 2020). The paper is structured as follows. In §2 Shusterman's definition of the art of eating is presented and analysed.In $\S 3$, I list the theoretical challenges of his proposal. In particular, I claim that his definition is still too tightly linked to food as the object consumed. In addition, a handful of reasons for not seeing the act of eating as art are provided. Next $(§ 4)$, by shifting from "the art of eating" into "aesthetic eating", I show how my position overcomes the difficulties faced by Shusterman's proposal. Lastly, the paper ends with the summary of my argument (§5).

\section{Shusterman's definition of the art of eating}

The definition established by Shusterman consists of two steps. First, the simple act of eating is distinguished from the more conscious and socially-oriented act of food consumption. Humans, unlike other animals, eat not only to satisfy hunger or thirst. They do it for other reasons as well (political, religious, moral and the like) and human food consumption is marked and shaped by culture to a high degree (Telfer 1996). This means that for the perception of food as objects to be eaten, aspects that go beyond the act of consumption itself are important (Korsymeyer 1999). Moreover, culture provides numerous tools, traditions and habits to critically discuss food and evaluate our gustatory choices and tastes. According to Shusterman, an aware form of eating ("eating know-how") is food consumption equipped with a certain kind of knowledge and sensibility regarding the history of gastronomy, cultivation of food ingredients and food preparation, as well as general rules of food pairing. Shusterman then takes a step further and sets up another level of eating:

I would propose a further distinction: between gastronomes who simply know how to select and enjoy good food (and who master the art of eating in this important but basic sense), and those gastronomes, who also know how to eat aesthetically in the fullest sense-beyond making good food choices and combinations. By this I mean those gastronomes whose knowledge of food and sensitive tasting is translated into an art of eating focused also on the aesthetic elements and qualities of the experience of ingesting food. (2016: 263)

Here we are provided with an important clarification, which might be treated as a sketch for the definition of the art of eating. The ability of selecting and enjoying food as well as knowledge in gastronomical history and practices is not enough for the art of food in a proper sense. What is needed is the transition from the consciously undertaken food choices and ways of gustatory enjoyment into discovering the aesthetic 
potential of food eaten and aesthetic qualities driven from the act of food consumption, as well as the fact that food is incorporated into the body. According to Shusterman, the art of (fine $)^{3}$ eating is characterized by the following two features.

First, the art of eating is essentially temporal and this feature is manifested at two levels. The first level is concerned with the obvious fact that eating is a temporally structured phenomenon: there is a sense of sequencing in the meals appearing at the table (e.g. tea is served after dinner) or the special order of dishes within a specific meal (e.g. appetizer is served before the main course). The second level refers directly to the sense of timing understood in bodily terms. That is, our body by necessity needs time to absorb and digest food: "[...] one mouthful leading to the next, or, more precisely, one mouthful leading to a complex sequencing of smelling, biting, tasting, chewing, swallowing, and breathing" (Shusterman 2016: 264). For example, when drinking a glass of chilled Riesling or Pinot Grigio our overall bodily (including gustatory) experience might vary greatly depending on the time taken between the sips or our posture (standing at the bar, sitting at the table or lying on the grass).

Second, in connection to its temporal nature, the art of eating is an artistic performance "[...] whose enjoyment is in the performative process of eating" (Shusterman 2016: 264). What is valued here is the act of food consumption. It also means that the art of eating displays different aesthetic features that the eaten objects does. Shusterman says: "Appreciating food's crucial contribution to the art of eating, I nonetheless argue that the art of eating goes well beyond the aesthetic qualities of the objects eaten" (Shusterman 2016: 264). This is the crucial point for defining the art of eating and Shusterman-being aware of thatimmediately refers to the possible objection that might be raised in order to challenge that feature. That is, one could claim that the enjoyment is rooted in the objects eaten (dishes) and not in the act of eating itself (I shall return to it later on). To address this potential issue he proposes to take a lesson from the philosophy of theatre, making the following analogy: the art of eating deepens the valued qualities of food and also refers to qualities that exceed the objects eaten in the same way the theatrical performance deepens the artistic value of the script. Thus, we can receive aesthetic enjoyment "[...] that go[es] beyond the tastes, smells, and visual forms of our food objects [...]" (Shusterman 2016: 264). ${ }^{4}$

${ }^{3}$ Shusterman refers here to "fine" art, but he actually does not make any extensive clarification about this notion further. I shall leave this matter unresolved as it is not entirely relevant to this paper. I suppose, however, that the predicate "fine" is used by Shusterman in order to emphasize that he is interested in art in a proper (and not just honorific) sense and I follow this way of understanding when reconstructing his position.

${ }^{4}$ Shusterman enumerates here the bodily movements connected with the act of eating, such as chewing, sipping, swallowing and the like. The specific elements of 
To sum up, while Shusterman postulates the existence of the art of eating, his goal is to provide the definition of this phenomena which will bring more precision to the philosophy of food and widely understood gustatory discourse. The art of eating is characterized by the two main features: (i) temporality and (ii) performativity. Moreover, the most philosophically important result of Shusterman's position is the claim that the aesthetic enjoyment of the art of eating goes beyond the objects eaten.

\section{Challenges}

Without doubt, Shusterman's view of the aesthetic process of consumption brings a considerable amount of novelty and precision into the contemporary philosophy of food and aesthetic theory. Shusterman is very much right in highlighting the temporal and performative aspects of the act of eating. I also concur with the analysis of the value of the art of consumption as a phenomenon contributing not only to the enrichment of our aesthetic life but also of human health.

In this section, however, I shall outline some tensions faced by Shusterman's definition. My main issue is with the mentioned proposal being still too focused on food appreciation and, thus, the process of eating not being (despite the explicit declaration) liberated from the objects eaten (dishes). These critical remarks will serve me as the ground for further inquiry where I would like to offer a more autonomous interpretation of the aesthetic act of eating (in $\S 4$ ).

Shusterman claims that the art of eating amounts to answering the question about the way in which an edible product should be consumed. In his words: "[...] how to eat and drink in terms of our modes and manners of ingestion can be constructed as the art of eating in its narrower and precise sense" (Shusterman 2016: 262). Since his proposal is to interpret at least some manifestations of the process of eating as an expression of art, I think one might ask for a certain sense of normativity of the aesthetic appreciation of that artform, e.g. if a given evaluation is correct or not (Zangwill 2003/2014). In other words, the aesthetic appreciation needs to be directed to the qualities of some entity qua the kind of the entity it is. ${ }^{5}$ If this is correct, then "how to eat and drink" is determined by the food itself rather than the way in which the food is consumed. And this "how" allows for eliciting properties (both aesthetic and non-aesthetic) from the objects eaten. The primary function of food in the art of eating is explicitly noticed by Shusterman. I evoke

the art of eating are: (1) posture; (2) movements; (3) the accessories for eating (e.g. choice of eating instruments); (4) selection of foods and their sequencing (acts of nonselection as well; also spontaneous selection), and (5) perception (269-274).

${ }^{5}$ This idea is notably presented and defended by Kendal Walton. In short, he claims that in order to correctly perceive an artwork we need to identify its features and categories (1970: 356). For the same issue explicitly concerning food and cuisines see also Ravasio (2018). 
his words: "Appreciating food's crucial contribution to the art of eating [...]" (2016: 264, my emphasis). Thus, in the art of eating, the food goes first. I do not want to say that this claim is substantially wrong. On the contrary, it could be perfectly fine, unless we state that a certain version of food consumption is art in itself. If we are keen to treat the art of consumption as a legitimate kind of art, as Shusterman does, it seems we need to make room for its "liberation" from the objects eaten. Thus, we have to identify its distinct features that do not belong to other artforms (e.g. to the culinary art understood as edible objects), if we would like to discuss the art of eating in a "narrow" sense. Moreover, the art of eating must be perceived as aesthetic on an equal level with food (e.g. a dish belonging to culinary art) and not as something only giving us "access" to the objects eaten.

It should be noted that the philosophy of theatre has already dealt with a similar problem. In the traditional view on the ontology of theatre, a performance was just an interpretation of the literary work and as such was denied an artistic status. Its role was only to give the viewers "access" to the literary work and it was judged according to its truthfulness to the literary work (Hamilton 2009a). It was showing that a theatrical performance is not just an interpretation of the literary work that allowed for treating it as an independent form of art (Osipovich 2006; Hamilton 2009b). As has been mentioned earlier, Shusterman anticipates this kind of worry and proposes to see the relationship between the object eaten and the act of eating as analogical to the one between a work of literature and theatrical performance. Suppose that a person is consuming an apple. In the very act of eating they have access to the qualities connected with what an apple is (how it tastes, smells and the like) as well as the qualities of the process of consumption in itself (e.g. rhythm of chewing). Thus, the eaten object is somehow "present" in the process of eating and some of its aesthetic qualities are "inherited" by the process of eating (and, naturally, the process of eating has different qualities than the apple as well). This is quite true with theatre, where the play "inherits" some properties of the script as the script is just one of the ingredients necessary for creating a theatrical performance. ${ }^{6}$ For example, Torvald Helmel's words "There can be no freedom or beauty about a home life that depends on borrowing and debt" are both a part of $A$ Doll's House as Henrik Ibsen's work as well as of a theatrical performance under the same title (although, in the first case they are written, whereas in the second case they are spoken).

However, whereas in the contemporary philosophy of theatre a theatrical performance is free from any obligations regarding a literary work, in Shusterman's view one of the key aspects of the art of eating

${ }^{6}$ According to this view a performance is never a performance of some other work, nor is it ever a performance of a text. The text of the literary work could be used as one of the ingredients to create a performance. See Hamilton (2007: 31-33). 
is to deepen the already existing properties of food. I do not think that such a role separates the act of eating from food in a sufficient degree. The potential aesthetic autonomy of the act of eating would be achieved only if we could value the act of eating without focusing so much on what we eat. Analogically, I can imagine a situation in which we are able to value a theatrical performance for its features no matter (mostly) what features are expressed by the work of literature.

In short, despite the undisputable value of Shusterman's proposal it suffers from being still too object-focused. Food plays an over-crucial role in the definition described above, which considers the art of eating something merely secondary and auxiliary when compared to culinary dishes. This does not seem enough for someone who, as Shusterman, truly wants to present the art of eating as an example art, not only in an honorific sense.

Unlike Shusterman, I suggest not to refer to the act of eating as a work of art. I do not claim that some processes of food consumption cannot constitute an art form. There is no doubt that the question of whether an act of eating can be art depends primarily on the definition of art that we agree to accept. In other words, if we accept a fairly liberal definition of art we can easily include the act of eating into the art world.

Having said that, I do not want to commit myself to any particular definition of art since, I hope, the more neutral my position is, the broader scope it has. Moreover, I am not entirely sure that seeing gastronomy (food as objects, eating as processes) through the lens of art ascribes any special value to it in itself. ${ }^{7}$ I concur with Ferran Adrià, a Catalan chef and food theorist, who argues that gastronomy and art are marked by different sorts of creativity and performativity ${ }^{8}$ and, as a result, "[g]astronomy is not an art and does not purport to be one" (Jaques 2018: 241). Not perceiving gastronomy within the art framework guarantees its autonomy and own language of communication. I do hope that my step is not a misinterpretation of Shusterman's intention. First, he does not give any definition of art at all ( $\mathrm{Nb}$. for someone this could be a reason for a potential critique) and seems to be more interested in art as a cultural practice emerging on different occasions. Moreover, Shusterman uses the term "art" as well as "fine art" to draw our attention to what he really thinks is truly treating the act of eating as a fully-fledged source of aesthetic experiences. I do share the opinion that the act of eating, under some circumstances, is a profound aesthetic phenomenon.

${ }^{7}$ In a similar spirit: John (2014).

${ }^{8}$ Various types of food and art histories are in length noted by Korsmeyer (1999: 141-145). 


\section{Aesthetic Eating}

In this section, I would like to propose such a definition of the act of eating-I label it "aesthetic eating" instead of "the art of eating"-in which what is appreciated is considered somehow separately from what is actually eaten. That is, in aesthetic consumption we value the qualities of the process, and not the qualities of food itself. It is suggested that the new proposal enables us to overcome the challenges faced by Shusterman's position as well as sheds light on the aesthetic function of the process of eating. I shall offer two understandings of aesthetic eating: a weak and a strong one. The former is Shusterman's claim reconceptualised, whereas the latter goes toward the aesthetic autonomy of food consumption.

I propose weak aesthetic eating (henceforth WAE) to be a practice focused on eliciting aesthetic qualities of food and drinks by following certain ready-made categories. By "ready-made" I mean rules and patterns that are traditionally associated with various kinds of foods and drinks that (supposedly) maximize their gustatory (and, thus, aesthetic) experiences. ${ }^{9}$ For example, we usually eat soup with a spoon or cut a beef steak with a knife, or have a glass of sparkling wine as an ice-cold drink, or a hot espresso as soon as it arrives at the bar counter. I shall then propose the following definition of WEA:

$x$ is WAE if: (i) $x$ is an act of food consumption of a dish $p$ by a person $O$; (ii) $x$ focuses on eliciting $p$ 's aesthetic qualities, and (iii) $O$ aesthetically appreciates $p$ through $x$.

WAE can be called "aesthetic" because it provides access to the aesthetic features of the eaten objects. (However, my definition does not presuppose that the process has or has not any aesthetic properties in itself.) WAE is an aware way of selecting and consuming food and drinks as well as a careful manner of detecting and enjoying the aesthetic potential of cuisines and food ingredients. In WAE the proper object of appreciation is a dish or a drink. ${ }^{10}$ Even if we experiment with the way we eat by trying to apply rules other than the ready-made categories (e.g. drink a cold espresso or eat melted ice-cream), in the end we are interested in what has changed in our perception and/or gustatory experience of the food. In other words, the possible value ascribed to every violation of a well-established approach towards certain kinds of food is judged according to our renewed or reconceptualised culinary experience. It is easy to notice that WAE defined in such a way is linked to Shusterman's proposal. Similarly to it, food plays the main part here.

${ }^{9}$ Food's ability to elicit aesthetic experiences has been defined on many occasions. See e. g. John (2014), Jacques (2014), Adams (2018).

${ }^{10}$ This seems to be coherent with John Dewey's opinion on food and aesthetics: "[...] seeing, hearing tasting, become aesthetic when relation to a distinct manner of activity qualifies what is perceived" (2008: 55). Thus, the act of eating might become an aesthetic experience (and WAE remains neutral about that) only when we take into account what is actually consumed. See also Koczanowicz (2016) 
However, Shusterman's proposal is stronger than WAE when treating the very act of eating as an object of aesthetic appreciation.

So far, I have referred to WAE, which has been motivated solely by my decision, but it is also worth mentioning that WAE can be somewhat "forced" by the unusual nature of the served dish. As an example I shall refer to Ferran Adria's Margarita (2005). It took the form of a snow-white cube with a dab of salty foam on top, which was eaten with a teaspoon. Its shape and consistency was meant to trick our intuitions about the margarita drink: an alcoholic beverage that must necessarily be in a liquid form. Imbibing this "drink" makes for an even more perplexing experience given the fact that it is served as an aperitif. Regardless if Adria's Margarita is a token of the so-called edible art or not (Andrzejewski 2018), we-as guests at the El Bulli restaurant-would have to decide in what way to approach this oddly shaped aperitif. Treating WAE in an experimental way might contribute to a discovery of new tastes, flavour combinations and modes of food preparation.

Now I would like to introduce the notion of strong aesthetic eating (henceforth SAE) understood as a practice focused on the aesthetic qualities of the act of eating. That is, SAE promotes paying attention and care to qualities belonging exclusively to the way of food consumption. SAE's definition is as follows:

$x$ is SAE if (i) $x$ is an act of food consumption of a dish $p$ by a person $O$; (ii) $O$ aesthetically appreciates $x$, and (iii) $x$ is appreciated mostly regardless of $p$.

In SAE we encounter an alternative object of appreciation that is the way of eating or drinking. Imagine that you are at quite a fancy restaurant enjoying contemporary Central European cuisine (say, a kind of "variation" on pierogi/pielmieni). In WAE you would enjoy the food as a wonderful dish, ideally re-interpreted according to the contemporary trends yet still faithful to its long and noble tradition of being a local specialty of the European periphery, whereas in the framework of SAE you would enjoy that dish as well as the manner in which you enjoy it.

I would like to support the argument for SAE's existence by referring to the recently emerged notion of the art of action (Nguyen 2020). ${ }^{11}$ In short, the art of action is the art in which artefacts are intentionally meant to elicit first-hand aesthetic experience of mental and physical processes. That is, we "appreciate the aesthetic qualities which arise in their own action" (Nguyen 2020: 2). Contrary to the art of artefacts where we are focused on objects "[t]he art of actions, on the other hand,

${ }^{11}$ Nguyen uses the term "art" in a very broad sense and his definition is not very much attached to it, see (Nguyen 2020: 4). For him, the most important thing is to include some processes as belonging to the group that deserves aesthetic attention and consideration. Hence, I do not see how supporting SAE by the notion of the art of action would automatically contradicts my intuition that SAE is not a kind of art. What I am doing here is rather supporting my claim by the broad idea of the aesthetics of action. 
are marked by distinctively self-reflective aesthetic appreciation. In these arts, the focus of appreciator's aesthetic attention is on aesthetic qualities of their own action." What should be stressed here is that in the art of action we gain access, evaluate and process first and foremost our own, personal experiences, which cannot be appreciated (and shared) by someone else. This is due to the definition, which states that only I have a full access to the qualities of the action I am currently performing. ${ }^{12}$ My suggestion is that SAE exemplifies a phenomenon, which could match the above description. In other words, SAE is an act in which what we aesthetically appreciate is the qualities emerging from the process of eating, which are are to be separated from the qualities of the food itself.

One step in establishing my argument is to notice that in WAE th food will always play the main role, as it is the central object of our appreciation and focus, but in SAE we can at least imagine a situation in which the way of eating may become more "important" than the object eaten. I do not want to claim here that the food should be fully ignored; my point is only that if we want to aesthetically appreciate the way of eating then we need to give it privilege over the food eaten (otherwise what would be appreciated is the food solely). To explore such a possibility, I support my claim with an observation that Shusterman's proposal focuses only on cases when the art of eating deepens the aesthetic pleasures provided by food and drink and - by doing so—goes beyond these pleasures. Thus, it acknowledges only the "positive" relationship between the food and the act of eating. In such a case, it's quite intuitive to perceive the act of eating as still bound to the objects eaten: the act of eating contributes to something already enjoyable. However, we could easily think of a different scenario. Aesthetic eating may not increase my pleasure, but could save me during a totally disastrous dinner. In other words, if we could find a situation in which aesthetic eating would translate into the aesthetic satisfaction with the act of eating even if the object consumed (dish) it is not particularly tasty (or we just do not fancy it), then SAE would prove itself a valuable claim.

Again, imagine that you have been invited to dinner by a dear friend. She has chosen a small, cozy restaurant run by an acclaimed chef with a strange surname you cannot even pronounce. You have both ordered a tasting menu, and before you have finished your welcome drink, the first dish arrives. From that moment your horror is about to begin... There is an oyster on your plate! You are not a big devotee of seafood at all and you actually do not remember when exactly you have last eaten these monsters! Despite the tragic situation you do not want to hurt your friend's feelings and decide to eat the oyster. She shows you how to hold the shell, what gestures to adopt in order to eat, what the accurate timing is, and at which moment you need to put the shell back.

\footnotetext{
${ }^{12}$ Naturally, some actions are experienced and evaluated form the outside and the inside (Nguyen 2020: 3).
} 
You follow her instructions accurately and the result is not shocking at all: you do not like the oysters. However, you actually liked the funny way of eating them and felt quite proud of yourself for stepping out of your comfort zone. ${ }^{13}$

My claim is that the specific nature of SAE reveals itself especially when it's accompanied with quite a trivial yet profoundly true observation about our live: it is evident that we do not always like certain objects or activities such as hiking, boat trips, silent cinema, karaoke, or a vast range of types of food and beverages. However, sometimes we find ourselves in a situation when we would like to change our attitude toward particular objects, tastes, flavours, or styles and undertake the effort to like these things even if we actually do not fancy them. ${ }^{14}$ In such a case we deal with the so-called acquired taste. "Acquired taste" according to Kevin Melchionne "jump-starts new satisfactions where I do not initially find them" (2007: $§ 1)$. It should not be confused with discovered taste. Unexpected flavour combinations, artworks or experiences one has never had before are subjects of taste preferences that are, metaphorically speaking, hidden in oneself. For example, when I was in primary school I never thought that a sandwich with salty crisps and olive oil could be my thing (I admit: it does not sound very appetizing). However, after the first bite I totally fell in love! For me this experience was an example of discovered taste: a certain situation just revealed some truth about my personal taste. It turned out that I have always liked that kind of sandwich but have just not realised that.

One could rise the objection that this is an argument in favour of liking the food and not the way of eating. This is partly true. However, I argue that if the aesthetic satisfaction driven from the act of eating is able to contribute to liking an initially disliked food then such way of eating is indeed a legitimate source of an aesthetic experience. What is more, in such a case we cannot simply say that aesthetic experiences are derived from food because we do not fancy it in the first place. ${ }^{15}$

${ }^{13}$ One could argue that in such a case we appreciate not the act of eating itself but rather a broader experience at the table that is distinct from food ingestion. This objection can be easily rebutted by noting the following two facts. First of all, a recent research has shown that eating experience is multisensorial in nature and brings many aspects that are not vividly (at first glance) connected with food consumption (see Spence, Youssef 2019). Secondly, Nguyen argues that in the aesthetic process we also include our experiences of the outside world that are related to the appreciated activity (2020: 9).

${ }^{14}$ An extreme example of such a case is analysed by Korsmeyer: "When disgust or revulsion is confronted and overcome, what was at first disgusting can become delicious" (2007: 149)

${ }^{15}$ One could rise another objection in a similar spirit: if the object of appreciation in SAE is not the food itself then it is a bit mysterious how SAE is supposed to help us acquire new taste. This potential issue might be undermined by noticing two points. First, in the process of acquiring new tastes (also in art) many factors are involved, e.g. decisions, intentions, social behaviours and project planning (Melchionne 2017, Korsmeyer 2002). Second, if we enjoy a certain way of eating then 
For acquired tastes the element of decision is necessary. As Melchionne puts it: "To acquire taste, we must decide to change the facts of our mental life. Acquired tastes are taken up despite the fact that, at the outset, we did not like them. Involving as if activity, acquired tastes are, by definition, never immediate, direct, or simple" (Melchionne 2007: emphasis in the original). So, an individual has to know that they do not like $x$ and decide to act as if they like $x$. It is worth noting that an acquired taste finally ends up in liking what we have previously only faked to like. Naturally, individuals cannot be forced (internally or externally) to like anything. Although, they might pretend to like something (a situation that results in a fake taste) or just stop making the effort to like something (acquired taste is not accomplished).

Having made a very brief outline of the issue of acquired taste, I suggest that aesthetic eating, if rightly adopted, is able to facilitate the process of developing acquired tastes. Firstly, WAE enables the subject to elicit the aesthetic properties from the object eaten. If we decided to really like something, then it would be valuable to maximize the aesthetic and gustatory impact of this object. For example, if someone has made a decision to like seafood, they should eat different kinds of seafood with attention and care in order to experience the seafood's taste fully. (Even though sometimes this might be really painful). It cannot be ruled out that new ways of eating seafood (with or without a spoon, with eyes closed, accompanied with some herb-based drinks and the like) might contribute to its overall taste and provide us with more reasons to become devoted admirers of seafood.

Secondly, in SAE we are focusing mainly on the fact that we're eating something and on the way in which we are doing it. For example, imagine that you are not a huge fun of whisky but many of your friends are and you often associate this alcoholic beverage with a nice vision of green Highlands or the rocky Islay island. What really might help you discover new experiences in the whisky world might be the way in which you consume that alcohol: your posture, other ingredients, the special way of pouring the mineral water, the manner of sipping, the timing in tasting and the mere fact that you're challenging yourself. In other words, it is not only the bodily movements that contribute to the aesthetic satisfaction but also the cognitive aspect of the whole process that plays an important role in the overall experience. ${ }^{16} \mathrm{SAE}$ invites one to value what could be called a meta-level of food consumption. It is true that we pay attention to how we eat but when it comes to the actual moment of consumption in many cases (however, surely,

we have to facilitate a certain kind of food in order to encounter this way of eating as frequently as possible. This might finally help us in acquiring a new taste.

${ }^{16}$ I do not claim that the bodily and cognitive aspects of our existence go apart (in particular, I do not believe in any sort of Cartesianism). However, in some cases we are able at least conceptually to distinguish between these two elements. For example, a decision to eat a certain dish belongs to the realm of cognition, yet, naturally, is very often facilitated by the bodily needs. 
not always) the way of eating becomes quasi-transparent: it's treated as a sort of "means" enabling us to taste the dish (WAE). SAE focuses on the higher level in the sense that one constantly pays attention and takes pleasures in something that is, in most cases, dimmed by food's features.

Liberating substantially the way of food consumption from what is consumed in SAE may also have a moral dimension. There is no need to say much about the obvious fact that individuals consume different kinds of food of varying quality, as well as its various quantities depending on their geographical location, socio-cultural conditions and financial abilities. Sometimes we eat what we can and not necessarily what we really want to. During mid-80s in a number of European countries people had very limited access to some of nowadays common goods such as citrus fruit, coffee, tea and some kinds of meat, to name just a few. Preparing a dinner for Christmas Eve for many families was quite a difficult task to accomplish since the meal itself was rather modest. However, despite the vivid shortcomings, many people took a considerable pleasure (I may risk to call it aesthetic in some cases) in the way in which food was prepared, put great effort into finding the ingredients (not always through official distribution channels) and showed a sort of creativity when they needed to replace some unavailable ingredients with more popular substitutes. SAE would help in dealing with the situation of shortage and unfriendly circumstances by focusing on the way of eating, e.g. consuming with dignity, responding to the behaviour of our loves ones, taking satisfaction from the mere fact that we did everything we could to prepare something to eat etc., and not being too much linked to what we actually ate. It should be emphasized that the suggested role of SAE is rather modest here but it still adds something to our moral realm. ${ }^{17}$

SAE does not work without any limitations. It is hard to argue that we can always receive aesthetic pleasure from the way in which we consume $x$, while at the same time completely not paying attention to what $x$ actually is. Although this is often the case, one can easily imagine a situation when we consume something so intensively flavoured or just profoundly not tasty that an individual simply cannot take even a tiny unit of pleasure from the act of eating in itself or they are not able to consume the food at all. Surely, a way of eating is ontologically dependent on what we eat: we can eat only when there is something to be eaten. Ontological priority does not mean, however, that judgments over the aesthetic qualities of food and the way of eating are not

${ }^{17}$ An analogy might be driven from the ritual of tea ceremony. In short, it expresses profound aesthetic and moral values and each element of the ceremony must be in the right place. However, perfection is not required. On the contrary, imperfection plays a crucial role for this ritual. Moreover, when done in the right way, the taste of the tea becomes of secondary importance compared to the way of preparing and consuming this warm beverage, which are the most important ones. See Saito (2007: 33-35; 2017). 
separable. They often go hand in hand, but SAE shows that it is not a matter of necessity. Moreover, I want to emphasize that in SAE we are not "blind" to what we are eating. On the contrary, we do notice the consumed food but SAE invites us to experience something far beyond that. ${ }^{18}$

What Shusterman's position and SAE have in common is that the object of aesthetic appreciation is the process of eating. I fully concur with Shusterman in setting up the project going beyond the food and seeking to value the somatic aspects of food ingestion. On the other hand, as I pointed out in $\S 3$, his proposal still suffers from being too object-focused: the food plays too big a role in his definition of the art of eating and needs to be liberated. Unlike Shusterman's art of eating, SAE offers more independence to the act of eating, not only regarding its aesthetic autonomy but also by seeing the process of eating on its own terms. Such a way of its conceptualisation opens up the possibility of taking a genuine aesthetic pleasure from it and provides an opportunity for several improvements if needed. That is, when we are predominantly focused on the qualities of the act of eating we might notice its weak points.

\section{Conclusion}

The aim of this paper has been to sketch a framework allowing to see the act of eating as an aesthetic phenomenon. What I want to show is that, under some circumstances, it is possible to receive aesthetic satisfaction from the act of food consumption, in which what is appreciated is, for the most part, considered separately from what is actually eaten. I called such a process "strong aesthetic eating" and contrasted it with "weak aesthetic eating". The latter is a conscious way of eating that is primarily focused on eliciting food's aesthetic features. Giving a considerable aesthetic autonomy to strong aesthetic eating does not automatically mean that food should not be valued aesthetically at all or valued to a lesser degree than the process of eating. On the contrary, I have argued that thanks to its aesthetic autonomy strong aesthetic eating is able to contribute to liking certain kinds of food (especially when we think of acquired tastes). I do hope that distinguishing the aesthetic pleasures of food from these of the act of eating will be able to not only enrich our aesthetic life but also deepen the aesthetics of our overall gustatory experience. ${ }^{19}$

${ }^{18}$ This is exactly why we cannot claim that in SAE what is appreciated in the end is the food itself (as in the case of WAE). If SAE belongs to process aesthetics then the proper object of appreciation in SAE are qualities arising from the whole action of eating, and these cannot be reduced to the object eaten. Thus, the object eaten and the way of eating it are strictly connected to each other, yet separable in terms of the aesthetic appreciation.

${ }^{19}$ I would like to express my gratitude to Alessandro Bertinetto, David Collins, Max Ryynänen, Mateusz Salwa, Marta Maliszewska and Monika Favara-Kurkowski, 


\section{References}

Adams, M. 2018. "The Aesthetic Value of Local Food.” The Monist 101 (3): $324-339$.

Andina, T., Barbero, C. 2018. "Can Food be Art?” The Monist 101 (3): 353361.

Andrzejewski, A. 2018. "How to Frame Edible Art." The Nordic Journal of Aesthetics 27 (55-56): 82-97.

Bonsdorff, P. 2012. "Pending on Art." Contemporary Aesthetics. Special issue: Artification.

Borghini, A. 2014. "Metaphysis of Natural Food." In P. Thompson and D. Kaplan (eds.). Encyclopedia of Food and Agricultural Ethics. New York: Springer: 1378-1381.

Borghini, A. 2015. "What is a Recipe?" Journal of Agricultural and Environmental Ethics 28: 719-738.

Dewey, J. 2008. Art as Experience. In idem, The Later Works, 1925-1953. Vol. 10. Carbondale: Southern Illinois University Press.

Hamilton, J. 2007. The Art of Theatre. Oxford: Blackwell.

Hamilton, J. 2009a. "The Text-Performance Relation in Theater." Philosophy Compass 4: 614-629.

Hamilton, J. 2009b. "Theatrical Performance and Interpretation." Journal of Aesthetics and Art Criticism 49: 307-312.

Jacques, J. 2014. "Food." In M. Kelly (ed.). Oxford Encyclopedia of Aesthetics, 2nd edition. Oxford: Oxford University Press: 63-67.

Jacques, J. 2015. "Main Issues on Gustatory Aesthetics." CosMo: Contemporary Studies in Modernism 6: 173-185.

Jaques, J. 2018. "Stovetop Philosophy: An Interview with Ferran Adria." The Monist 101 (3): 237-246.

Jacques, J., Adrià, A. 2015. "For an Applied Philosophy of Gastronomy." CosMo: Contemporary Studies in Modernism 6: 163-172.

Koczanowicz, D. 2016. “John Dewey: A Culinary Perspective.” Pragmatism Today 7 (2): 88-94.

Korsmeyer, C. 1999. The Making Sense of Taste. Ithaca: Cornell University Press.

Korsmeyer, C. 2002. "Delightful, Delicious, Disgusting." Journal of Aesthetics and Art Criticism 60 (3): 217-225.

Mancioppi, E., Perullo P., 2020. "Estetica aromatica. Odore, politiche dell'atmosfera e impegno percetivo." Rivista di estetica, 73 (1): 118-135.

Michel, C.,Velasco, C., Gatti E., Spence Ch., 2014. "A taste of Kandinsky: assessing the influence of the artistic visual presentation of food on the dining experience." Flavour 3 (7): 1-10.

Melchionne, K. 2007. "Acquired Taste." Contemporary Aesthetics, vol. 5.

Melchionne, K. 2017. "Aesthetic Chioce." British Journal of Aesthetics 57 (3): 283-298.

as well as two anonymous reviewers for their helpful comments and constructive criticism on this paper in draft. Special thanks go to Iris Vidmar Jovanović for her constant support and valuable advice. I am also indebted to the Faculty of Philosophy at the University of Warsaw for their generous financial and administrative support whithout which this research could not be conducted. 
Nguyen, C. T. 2020. “The Arts of Action.” Philosophers' Imprint 20 (14): $1-27$.

Osipovich, D. 2006. "What is a Theatrical Performance?" Journal of Aesthetics and Art Criticism 54: 461-470.

Perullo, N. 2016. Taste as Experience. The Philosophy and Aesthetics of Food. Foreword by M. Montanari. New York: Columbia University Press.

Ravasio, M. 2018. "Food Landscapes: An Object-Centered Model of Food Appreciation." The Monist, 101 (3): 309-323.

Saito, Y. 2007. Everyday Aesthetics. Oxford: Oxford University Press.

Saito Y. 2017. "The Role of Imperfection in Everyday Aesthetics." Contemporary Aesthetics 15.

Shusterman, R. 2016. "Somaesthetics and the Fine Art of Eating." In S. Irvin (ed.). Body Aesthetics, Oxford: Oxford University Press: 261-280.

Spence, Ch., Youseef J. 2019. "Synaesthesia: The multisensory dining experience." International Journal of Gastronomy and Food Studies 18.

Telfer, T. 1996. Food for Thought. London: Routledge.

Walton, K. 1970. "Categories of Art.” The Philosophical Review 79 (3): 334367.

Zangwill, N. 2003/2014. "Aesthetic Judgment." Stanford Encyclopedia of Philosophy. E. Zalta, (ed.), accessed June 29, 2020. 